\title{
Matrizes teóricas dos saberes elementares matemáticos da escola primária em tempos de primeira república
}

Theoretical frameworks from the mathematicselementary

knowledge in primary school in first republic times

Matrices teóricas de los conocimientos elementares matemáticos de la escuela en tiempos de primera republica

Neuza Bertoni Pinto*

Pontifícia Universidade Católica do Paraná (PUCPR), Curitiba, PR, Brasil

\section{Resumo}

Na história da educação matemática são recentes os estudos que investigam filiações teóricas dos saberes elementares ofertados nos primeiros anos escolares. Este artigo, centrado nos saberes elementares matemáticos da escola primária das primeiras décadas do século XX, dialoga com estudos já realizados no Grupo de Pesquisa de História da Educação Matemática - GHEMAT, acerca dos sentidos conferidos ao elementar no

NBP: Doutora em educação, e-mail: neuzabertonip@gmail.com 
âmbito dos saberes elementares, dentre outros o que trata do simples e complexo no ensino da Aritmética (VALENTE, 2015). Centrando a discussão em torno do termo elementar, o presente estudo busca compreender repercussão de matrizes teóricas na organização dos saberes elementares matemáticos prescritos para o ensino primário do Paraná. Analisa o conceito do ponto de vista filosófico e pedagógico a partir de Descartes, Condorcet e Pestalozzi e busca relações dessas matrizes teóricas com a organização dos saberes elementares matemáticos programados para a escola primária em tempos de Primeira República. Para as análises são consultados programas oficiais e livros didáticos de Aritmética prescritos oficialmente para a escola primária do Paraná, entre 1903 e 1932. O estudo mostra que o método utilizado na organização dos saberes elementares matemáticos expressa a matriz teórica que fundamenta o ensino ofertado.

Palavras-chave: História da educação matemática. Saberes elementares matemáticos. Escola primária.

\begin{abstract}
In the history of mathematics education, studies investigating theoretical affiliations of elementary knowledge offered in the early school years are recent. This article focused on mathematical basic knowledge of primary school on the first decades of the twentieth century, dialogues with previous studies in GHEMAT, about the meanings of elementary under the elementary knowledge, among others dealing with simple and complex in the teaching of arithmetic (VALENTE, 2015). Focusing the discussion on the elementary term, this study seeks to understand impact of theoretical frameworks in the organization of elementary mathematical knowledge prescribed for primary education of Paraná. Analyzes the concept of philosophical and pedagogical point of view from Descartes, Condorcet and Pestalozzi and seeks relations of these theoretical frameworks with the organization of elementary mathematical knowledge scheduled to primary school in times of First Republic. For the analysis will be consulted official programs and textbooks of Arithmetic officially prescribed for the primary school of Paraná, between 1903 and 1932. The study shows that the method used in the organization of elementary mathematical knowledge reveals the theoretical matrix that underlies the education offered.
\end{abstract}

Keywords: History of mathematics education. Mathematics elementary knowledge. Primary school. 


\section{Resumen}

En la historia de la educación matemática son recientes los estudios que investigan afiliaciones teóricas de los conocimientos elementares ofrecidos en los primeros años escolares. Este artículo enfocado en los conocimientos elementares matemáticos de la escuela primária de las primeras décadas del siglo XX, dialóga con estudios ya realizados no GHEMAT, acerca de los sentidos comprobados a elemental en lo ámbito de los conocimientos elementares, entre otros o que trata del sencillo a complejo na enseñanza da Aritmética (VALENTE, 2015). Centrando la discusión en torno del término elemental, el presente estudio búsqueda comprender la repercusión de matrices teóricas en la organización de los conocimientos elementares matemáticos prescritos para el enseñanza primária del Paraná. Analiza el concepto del punto de vista filosófico y pedagógico de Descartes, Condorcet e Pestalozzi y búsqueda relaciones de esas matrices teóricas con la organización de los conocimientos elementares matemáticos programados para la escuela primária en tiempos de Primera República. Para las análisis serán consultados programas oficinales y libros didácticos de Aritmética prescritos para la escuela primária del Paraná, entre 1903 y 1932. El estudio muestra que el método utilizado en la organización de los conocimientos elementares matemáticos revela la matriz teórica que fundamenta el enseño ofrecido.

Palabras clave: Historia de la educación matemática. Conocimientos elementares matemáticos. Escuela primária.

\section{Introdução}

Em seu livro "Inscrever \& Apagar", o historiador francês Roger Chartier (2007), adotando variadas fontes literárias dos séculos XI a XVIII, depreende representações de práticas de escrita, dentre elas, as de um dramaturgo veneziano cujas encenações destacam-se características de personagens como a astúcia da estalajadeira Mirandolina que para seduzir o Cavalheiro que dizia desprezar as mulheres, provoca um encontro 
levando para o quarto dele finos lençóis de linho, lençóis que segundo ela, havia embanhado e bordado especialmente para cavaleiros qualificados.

Mirandolina, como outras moças de seu tempo, aprendera habilidades próprias para mulheres, o que lhe permitia preparar um delicioso guisado que infalivelmente deveria derrubar o cavalheiro em suas armadilhas. Suas qualidades não paravam por aí. Ela também conquistara o poder totalmente masculino da escrita.

Desejoso de deixar o albergue para evitar os perigosos encantos de Mirandolina, o Cavalheiro pede sua conta. Fabrício, o criado com quem por fim ela se casará, declara: "A patroa a está preparando" (p. 248). O Cavalheiro se impressiona: "É ela quem faz as contas? Ele responde: Sim, sempre ela, desde quando seu pai era vivo. Ela sabe escrever e contar como ninguém, melhor do que qualquer caixeiro" (p. 249).

A narrativa descreve a personagem como:

[...] "amável e inteligente, trabalhadora e espirituosa, encantadora e vaidosa e, afinal de contas, astuta, pois Mirandolina sabe bordar, como também escrever, cozinhar e fazer contas. Em face do mundo masculino dos tecelões venezianos, ela é a encarnação de uma mulher independente, inteligente e racional, que larga a agulha e enverga a pena" (CHARTIER, 2007, p. 249).

Com esse prólogo o historiador lembra que ao longo da história da humanidade, mulheres não tão jovens bordaram a escrita, seguiram normas e tarefas e aprenderam saberes específicos. Contudo, "ao mesmo tempo quando somente deveriam ser leitoras obedientes, a escrita com a agulha e depois com a pena, permite que construam outra imagem de si mesma menos submissa à ordem masculina" (p. 247).

A opção por iniciar pela narrativa de Chartier não foi para sublinhar artes femininas, e sim ressaltar saberes elementares que prosperaram nas sociedades modernas, desde os afazeres do artesão, do tecelão, do mercador e do escriba.Ao abrir um baú de narrativas, a obra de Chartier descortina e aponta para a importância e utilidade de determinados saberes para a vida prática, a denominada base que em outros tempos daria 
significado ao espírito prático da escola primária ao se dispor a proporcionar saberes elementares úteis para a formação de muitas gerações.

O termo elementar, como tem afirmado Trouvé (2008, 2010), não foi discutido apenas no campo da filosofia, por Aristóteles, Locke, Descartes, dentre outros, também foi discutido no campo da pedagogia por pensadores reconhecidos no campo da educação, como Condorcet, Pestalozzi.

O fato do termo "elementar" ter assumido vários sentidos ao longo da história, estudos recentes sobre saberes elementares matemáticos têm trazido novas análises e permitido avançar sobre a temática, de modo especial, no âmbito de dois projetossem curso no cenário educacional, um de âmbito nacional, outro, de cooperação internacional. ${ }^{1}$

Valendo-se de discussões já levantadas por Trouvé (2008, 2010) e Valente (2015), acerca do termo discutido, este artigo problematiza matrizes teóricas dos saberes elementares matemáticos advindas dos campos da filosofia e da pedagogia, buscando compreendê-las nas organizações programáticas de um dos estados brasileiros, o estado do Paraná. As matrizes estão prescritas oficialmente para o ensino da Aritmética da escola primária do estado do Paraná, do período de 1903 a 1932.

Neste artigo, buscaremos analisar matrizes teóricas dos saberes matemáticos, chamados de elementares e que foram dispensados pela escola primária nos primeiros tempos republicanos no Brasil. Para o alcance desse objetivo, o artigo inicia com filiações culturais, apontadas por Hébrard (1990), acerca da trilogia saber ler, escrever e contar e a configuração desses saberes na escola primária brasileira nas duas primeiras décadas da primeira república (1890-1910).

1 O projeto nacional "A Constituição dos Saberes Elementares Matemáticos: a Aritmética, a Geometria e o Desenho no curso primário em perspectiva histórico-comparativo (1890-1970)", aprovado pelo CNPq e o projeto de cooperação internacional "L'enseignement des mathématiques à l'école primaire, XIXe XXe siècle. Études comparatives, Brésil-France", aprovado pela CAPES/ COFECUB, encontram-se em execução no Grupo de História da Educação Matemática, GHEMAT, coordenado pelo Prof. Dr. Wagner Rodrigues Valente e dos quais participamos juntamente com pesquisadores de inúmeras universidades brasileiras e francesas dentre elas, a PUCPR. 
No segundo momento, serão analisadas matrizes teóricas dos saberes elementares da escola primária, cujas problematizações têm permitido avançar os estudos sobre os saberes elementares matemáticos no ensino primário. O terceiro momento analisa o legado das matrizes analisadas para o alcance das finalidades da escola primária dos primeiros tempos republicanos, intentando compreender a natureza dos objetivos propostos, se o almejado era um saber propedêutico ou um saber imprescindível para a sociedade moderna.

O texto é finalizado com as considerações sobre repercussões das matrizes, analisadas na constituição dos saberes elementares matemáticos, na base da formação das gerações do início da república no Brasil.

\section{Da história dos saberes elementares}

Quando se trata da escolarização dos saberes elementares na época moderna, Hébrard (1990) afirma que nas escolas de primeiras aprendizagens esses saberes eram "savoir-faire", ou seja, saberes não assinalados na hierarquia das ciências, como os que acompanharam toda a instrução cristã na França moderna, "os saberes ensinados pareceriam ser então não disciplinas mas diferentes facetas das práticas ordinárias da instrumento necessário à gestão da vida e de suas ocupações, por mais comuns que fossem" (p.65).

Na Itália, segundo Hébrard (1990), a precocidade da cultura escrita se manifesta avançada em fins da Idade Média e no Renascimento, tempos em que mercadores, artesãos, comerciantes, artistas, contadores, alguns operários e algumas mulheres aprendem a ler e que a esse saber é acrescentado saberes dos aritméticos que acompanham os fazeres dos comerciantes.

O historiador observa que as formas disciplinada e constituída, que ao longo da história foram assumindo esses saberes, tinham em vista garantir para a criança ou jovem, o estatuto propedêutico da escalada do conhecimento. Ao distinguir dois tipos de finalidades atribuídas a esses saberes, Hébrard remete à problemática que historicamente envolveu a 
trilogia de saberes: o ler, escrever e contar, saberes programados ora como aprendizagens primeiras, ora configurados como artes imprescindíveis para a vida nas sociedades modernas.

Que vínculos os saberes elementares matemáticos do ensino primário mantiveram com as duas finalidades apontadas por Hébrard em tempos de Primeira República?

Apesar de ser uma temática ainda pouco investigada em nosso país, estudos recentes sobre a constituição dos saberes elementares matemáticos mostram que a Aritmética teve um lugar permanente nos programas de ensino deste período ${ }^{2}$.

A constituição de tais saberes é uma temática sob o ponto de vista histórico ainda pouco averiguada em nosso país. Contudo, inúmeras fontes históricas localizadas por pesquisadores de diferentes estados brasileiros têm permitido compreender que desde os primeiros anos de instalação do modelo grupo escolar ${ }^{3}$ em nosso país, finais século XIX, tempos de criação dos primeiros grupos escolares no Brasil, modelo que perdurou até 1970, por ocasião da extinção da escola seriada de quatro séries, quando o ensino primário junta-se ao ginásio passa a compor o então Ensino de Primeiro Grau (Lei 5692/1971), tais saberes sofreram inúmeras modificações em suas configurações.

A nova modalidade de escola primária protagonizada no período do Grupo escolar, escola graduada e organizada em quatro séries com um professor para cada série, foi um modelo escolar representativo da modernidade educacional brasileira não somente em termos de organização pedagógica, como também em relação à qualidade do ensino ofertado à população. Considerado uma escola de excelência (SOUZA, 2009), na primeira metade do século XX, esse modelo escolar foi espaço fértil para

2 Ver Anais dos XI e XII Seminários Temáticos realizados, respectivamente, em 2014 na UFSC: http://seminariotematico.ufsc.br e em 2015, na PUCPR: http://www2.td.utfpr.edu.br/seminario_ tematico/index.php

3 Grupo Escolar- modelo de escola seriada em quatro series e com um professor para cada turma. Criada em 1890, no Brasil, essa modalidade escolar só foi extinta em 1970. 
apropriação de ideias e fazeres defendidos nos meios intelectuais e científicos do período.

Compreender como essa escola abordou saberes matemáticos ${ }^{4}$, em que base teórica as matérias que ensinavam esses conhecimentos estavam apoiadas, têm suscitado maior compreensão das matrizes filosóficas e pedagógicas que idealizaram e legitimaram métodos e noções sobre a elementaridade de saberes, tendo em vista garantir uma finalidade educativa às aprendizagens da base escolar.

O ensino das quatro operações, como indicam os códigos e programas oficiais das primeiras décadas do século XX por muito tempo, desde os tempos imperiais, seguiu orientado pelo método intuitivo que buscava imprimir-lhe um caráter prático e instrumental na busca de alcance da finalidade almejada. Método que traz na sua concepção uma pedagogia que contrasta com posições filosóficas que tratam do elementar e da elementaridade.

Para os historiadores Chervel (1990) e Julia (2001), a escola primária tem sua cultura própria, organizada não em torno de um saber especializado (disciplinas escolares) mas a partir de saberes práticos envolvidos em matérias ligadas entre si e dinamizadas por ações docentes que irão conferir-lhe o espírito de um saber mais prático do que teórico. Tal finalidade não é, segundo os historiadores da cultura escolar, facilmente observada nos conteúdos programáticos, revela-se com maior intensidade no "aparato pedagógico" que os envolve.

A compreensão da cultura escolar na perspectiva de Julia (2001), requer um olhar histórico não somente direcionado às normas oficialmente prescritas para o ensino, mas também um olhar para as formas como foram apropriados os saberes envolvidos nos conteúdos programados, nos materiais e dispositivos utilizados nas aulas, que processos avaliativos aferiram o desempenho dos alunos, e a quais métodos de ensino os professores

4 Por saberes elementares matemáticos estamos considerando a Aritmética, a Geometria e o Desenho ensinados na escola primária, ou seja, os conteúdos a ensinar e a forma essas matérias eram ensinadas na primeira república. 
recorreram. Na vertente da história cultural, a compreensão das finalidades dos saberes elementares matemáticos apresenta-se complexa quando se considera a escola como um espaço dinâmico criativo, sujeito a permanências e transformações. Dessa forma, o que altera nos saberes elementares matemáticos quando os programas vão incorporando pressupostos das diferentes ciências? Os saberes dispensados pela escola primária foram mais utilitários, instrumentais ou mais culturais e científicos?

Uma representação ainda presente no imaginário coletivo é a de que os saberes elementares matemáticos se resumem em "saber fazer contas e resolver problemas aritméticos”. Também, de que a matemática moderna foi responsável pela desestabilização de um sólido programa que assegurava o "espírito prático" da formação escolar do cidadão e do trabalhador. Entender a complexidade de um saber escolar inclui olhar o que e como as ideias de pensadores modernos impactaram movimentos e reformas educativas em relação aos modos de ensinar e aprender na escola primária.

Uma obra que tem contribuído para ampliar a compreensão dos saberes elementares é a do francês Alain Trouvé (2008, 2010), autor que em suas análises sistematiza uma teoria do saber elementar, afirmando que os saberes elementares não são tão simples quanto parecem. Afirmação esta, que vem repleta de argumentos de que esses saberes possuem diferentes filiações teóricas, dentre elas as filosóficas e as pedagógicas.

Para o autor, um saber elementar não é, portanto, algo simples como é geralmente tratado em tendências de Escola Nova. Essas tendências que descrevem a dinâmica da aprendizagem como uma passagem do simples ao complexo, do fácil ao difícil, do próximo ao distante, do concreto ao abstrato.

Segundo Trouvé (2008), a complexidade da noção requer problematização e um tratamento histórico, considerando que nos contextos nos quais foi elaborada estão presentes nuances de duas principais naturezas: filosóficas e pedagógicas. 
A noção de elementar não é, também, ultrapassada. Na medida em que ela guarda diferentes compreensões, remete às exigências epistemológicas, aos saberes de base - o fundamental, aos objetivos nucleares da escola que os ministra, aos aspectos políticos (uma base comum de conhecimentos) e éticos (emancipação universal), singularidades que apontam para a existência de vínculos entre a cultura escolar e outras culturas, como têm observado Hébrard (1990) e Julia (2010).

Ao defender a cultura pedagógica que envolve esses saberes Trouvé (2008), traz à tona o não lugar da pedagogia na cultura considerada legítima, tecendo uma crítica à inércia das reformas em curso no sistema educativo.

\section{Saberes elementares do ponto de vista filosófico}

Trata-se de uma questão importantíssima para a compreensão dos saberes elementares ao distinguir duas tradições que interferiram na organização da programação da escola primária: a originária da corrente filosófica racionalista e a outra da corrente filosófica empirista.

Como afirma Trouvé (2008), por se tratar de uma noção considerada como bastante complexa e que envolve uma tensão entre simplicidade e complexidade (o que é simples para um pode ser complexo para outro), dualidade, que do ponto de vista filosófico remete às ideias de Aristóteles, primeiro a propor uma teoria do conhecimento elementar, ou seja, de que os saberes não se reduzem a uma simples reunião de dados esparsos da experiência mas têm um caráter sistemático que permite religá-los, explicá-los desde seus princípios, desde seus elementos. Tratase de organizá-los racionalmente "encadeando proposições que permitam construir uma visão unificada dos saberes, um espírito de acordo com o espírito verdadeiramente enciclopédico" (TROUVÉ, 2008, p. 50).

Em Descartes e Locke as ideias simples são colocadas como primeiros conhecimentos. Enquanto o racionalista Descartes buscava origens dessas ideias na ordem da razão, via dedutiva, Locke vai interessar-se 
por sua gênese, a partir de fatos empíricos, via da indução. Ao destacar a simplicidade dos primeiros conhecimentos, Descartes refere-se ao progresso do conhecimento, do simples ao complexo.

Em Locke e Condillac, o elemento está enraizado na sensação e não na atividade de entendimento. Os conhecimentos partem das experiências do sujeito que conhece, enquanto que para D'Allembert, os saberes são originários tanto da experiência quanto do entendimento e tal como Aristóteles, o ideal epistemológico é o enciclopédico (TROUVÉ, 2008).

Para a instrução primária, Locke recomenda que para a criança ser introduzida aos saberes elementares, dentre eles a Geografia, Aritmética, Astronomia, Geometria, Cronologia e a História:

O ponto de partida deverá ser sempre as noções mais sensíveis e claras: deve lembrar-se que o começo está nos sentidos, que há de ensinar-se uma coisa por vez e passar à seguinte só quando cada conhecimento está convenientemente fixado. Se procederá, pois, gradualmente (LOUGHLIN,1967, p. 95).

Para Locke o elementar é um saber cuja natureza são as ideias simples, originárias das sensações, fundamentadas na experiência cujo ideal é partir do conhecido e chegar ao desconhecido, ao saber enciclopédico. Para isso recomenda que para que a criança seja estimulada a novas aprendizagens, seja convertido em pequeno mestre de outros com menores conhecimentos que ele.

Como se nota, entre os filósofos, a noção de elementar é polissêmica, eles divergem em relação aos métodos e às abordagens pedagógicas. Enquanto Descartes sugere caminhar da ideia confusa à uma ideia clara e distinta, rumo a uma autodidaxia. Locke aproxima-se de Aristóteles, parte das sensações para a inteligibilidade, cujo ideal é o ensino.

Nesse sentido, mais que uma parte, o elemento é um elo da cadeia de saberes, "um princípio de inteligibilidade das coisas" (TROUVÉ, 2008, p.150), portanto, do ponto de vista filosófico, uma noção fundamentalmente complexa. 


\section{Saberes elementares do ponto de vista pedagógico}

Do ponto de vista pedagógico, Trouvé (2008) analisa a noção do saber elementar em duas fontes diferentes: em Condorcet, a fonte instrucionista, que de acordo como autor, apresenta em detalhe uma teoria do elementar condicionada à educação pública. Já em Basedow e Pestalozzi, a fonte vista como educacionista, que além do saber para o cidadão republicano, considera a criança que aprende.

É importante observar que Trouvé considera uma linha divisória entre o elementar em Condorcet (linha instrucionista francesa) e o elementar pensado por Pestalozzi (linha educacionista germânica).

Representante do racionalismo enciclopédico e do método analítico, Condorcet sistematiza os saberes elementares, de acordo com o estatuto da instrução pública, contemplando, na elementarização, princípios estéticos e da educação do cidadão cujo centro da instrução são os conteúdos. Defendendo uma instrução universal, propõe popularizar o saber científico, a partir da generalização de seus elementos.

De acordo com Trouvé (2008), em Condorcet é necessário compreender a instrução elementar no sentido de uma instrução de verdades, elementos das ciências, o que exclui a ideia de uma instrução simplesmente rudimentar e unicamente utilitária (p.180)".

Ainda no campo pedagógico, o elementar encontra-se bem delineado em Pestalozzi, educador alemão, que para circunstanciar uma nova compreensão do elementar, nelas encontrando duas fontes de elementares, a qual considera o "simples" residente na abstração e outra que considera o "simples" residente na "concretude".

Para Pestalozzi, a escrita é uma espécie de desenho linear especial que não é senão um jogo para a criança, uma vez que seus olhos e suas mãos foram convenientemente exercitados. Tanto para a escrita, quanto para o desenho, ele recomenda a ardósia e o crayon devendo ser preferidos à pena e ao papel. O ensino experimental da Aritmética é feito por meios concretos. Antes de conceber os números in abstracto, o aluno vai tratá-los em seu valor material, adicionando objetos reais, cerejas, nozes 
etc. Antes de calcular os símbolos 10, 12, é preciso que tenha contado materialmente os dedos da mão, os doze meses do ano. Os primeiros cálculos devem ser feitos de cabeça, mentalmente, sem o recurso de papel. Pestalozzi é, portanto, um dos promotores do cálculo mental. A instrução elementar no plano de Pestalozzi visa todas as faculdades, as mãos, tanto quanto a cabeça e o coração, segundo suas próprias expressões. O primeiro dever do educador é sem dúvidas formar homens (PESTALOZZI, 1947).

O elementar, pensado por Pestalozzi, é o que parte do empirismo e está centrado na educação dos sujeitos, nos valores morais e na edificação de uma nova sociedade. Pestalozzi é o principal representante do elementar do ponto de vista dos sujeitos.

Em É crits sur la Méthode, v. 5, Pestalozzi (2013) escreve sobre as grandes leis que regem o processo metódico. A primeira, lei da simplificação elementar, focaliza princípios e base dos elementos simples, aquilo que considera como base dos saberes: saber fazer e saber ser. Ainda, defende e descreve o método intuitivo, do concreto ao abstrato, do fácil ao difícil. Para ele, a educação elementar deve contribuir para que o número, a forma e a linguagem, elementos fundamentais na educação do indivíduo, sejam conhecimentos presentes na formação integral e emancipação dos indivíduos.

Na obra Le ChantduCygne (1947), Pestalozzi faz observações sobre como deveria ser considerado, na formação elementar, o estudo natural dos números e das formas, de maneira diferente da arte que consiste em exercer mecanicamente a arte de contar e medir.

Portanto,

“[...]o estudo natural dos números e das formas não é uma arte que consiste exercer mecanicamente a faculdade de contar e medir. O ponto de partida não reside, pois, em fórmulas, por mais engenhosas que sejam, tendem a simplificar e abreviar as operações de cálculo e da medida" (PESTALOZZI, 1947, p. 94). 
Essa discussão pode ser encontrada no estudo de Oliveira (2015), ${ }^{5}$ que analisa com muita propriedade o método utilizado por Pestalozzi para tratar dos saberes elementares matemáticos.

O método, denominado de método intuitivo, trata da experiência dos sentidos, explorando faculdades de intuir, refletir, comparar, medir, desenvolver a percepção, habilidades mentais permitindo o contato direto da criança com as coisas as quais a rodeiam e que fundamentalmente atestam o espírito prático da escolarização inicial da criança, sua entrada natural ao mundo em que vive.

Ao focalizar o legado do método intuitivo proposto por Pestalozzi, Oliveira (2015) destaca que para aprender a contar:

[...] parte-se sempre da concretude dos objetos, das coisas que estão ao alcance dos sentidos da criança Ensinar a contar e a calcular por meio de coisas ilustradas que possam caracterizar a 'nova' prática de ensino dos saberes aritméticos: trabalhar simultaneamente o conceito de número com os alunos, em um espaço curto de tempo e com o abandono da lição de cor, valendo-se das lições pelas coisas ( OLIVEIRA, 2015, p. 39).

As lições de coisas têm despertado o interesse de historiadores da educação brasileira e dentre os inúmeros estudos destaca-se o realizado por Valdemarin (2004), que muito tem contribuído para as recentes investigações do método intuitivo na constituição dos saberes elementares matemáticos.

\section{Saberes elementares da Aritmética ensinada no ensino primário}

As pesquisas em torno da temática dos saberes elementares matemáticos têm permitido avançar as discussões da história da educação matemática ${ }^{6}$ trazendo novas compreensões dos discursos que circulam

\footnotetext{
5 Publicado no vol. 4, dos Cadernos de Resumos, organizado por Valente (2015a).

6 A temática também é discutida em nível mais amplo, em pesquisas desenvolvidas no projeto de
} 
sobre organização programática dos conteúdos, os métodos e dispositivos didáticos utilizados no ensino dos anos iniciais, as formas de apropriação em documentos oficiais e escolares, especialmente em livros didáticos indicados para as escolas tendo em vista o alcance das finalidades educativas.

Os estudos já realizados e em curso no GHEMAT, de uma certa forma favorecidos pela criação de um espaço virtual do projeto ${ }^{7}$, que ao disponibilizar fontes históricas sobre saberes elementares matemáticos, vêm possibilitando um fecundo diálogo entre os pesquisadores de diferentes regiões brasileiras e estimulado estudos histórico-comparativos que colocam em relação saberes contemplados em diferentes escalas ${ }^{8}$.

Nesse sentido, Valente $(2015 \mathrm{a})^{9}$ destaca a importância de especificar o sentido dado aos saberes elementares matemáticos no ensino primário. Mas sempre considerando a forma peculiar como este configurava suas matérias, observando que os mesmos não se restringiam aos temas prescritos na programação da Aritmética, Geometria e Desenho, no entanto permeavam outros espaços curriculares como os ocupados pela Cartografia e Trabalhos Manuais, matérias que muito contribuíam para conferir o sentido prático da formação almejada pela escola primária em tempos áureos dos grupos escolares. Em especial, o estudo do autor aponta o envolvimento dos saberes elementares com diferentes tradições teóricas herdadas do iluminismo em suas distintas vertentes intelectuais, cuja reelaboração do racionalismo após a Revolução Francesa inspira uma educação não mais centrada nos conteúdos, mas em valores morais e uma nova sociedade projetada a partir de uma nova pedagogia.

cooperação internacional, Brésil-France. Ver Seminários realizados na Université de Limoges e Collège de France, em Paris. http://repositorio.ufsc.br/handle/123456789/1769.

7 http://repositorio.ufsc.br/handle/123456789/1769.

8 Em 2013, uma das atividades do projeto de Cooperação Brasil-França foi realizado na Pontifícia Universidade Católica do Paraná: “Formação de Professores para a Escola Primária no Brasil e na França em tempos de Ensino Intuitivo e Escola Nova" com participação de pesquisadores brasileiros e franceses.

9 VALENTE, W. R. Saberes Elementares Matemáticos. Elementar. Cadernos de Trabalho. N. 1. São Paulo: Editora Livraria da Física, 2015b, p. 15-49. 
Tais fundamentos encontram-se em Pestalozzi, educador que irá preconizar métodos modernos para bem formar o caráter do homem.

Diferente do cultivo da razão que alimentou o pensamento intelectual do século precedente e que defendia a instrução a partir da aquisição dos conteúdos (distribuídos em disciplinas escolares).

[...] À escola, à pedagogia moderna caberá a formação do caráter. E os novos princípios educativos opõe-se fundamentalmente ao projeto de formação racional vindo da aquisição de conteúdos postos nas disciplinas escolares. $\mathrm{O}$ centro de gravidade do ser não mais seria a sua razão, como no século precedente, ele transformou-se na ação do indivíduo. E, mais: sua razão passa a ser vista como um produto da sua adaptação do ser às suas condições de vida (VALENTE, 2015b, p. 23).

O elementar, no senso comum referido como coisas simples ou aquilo que se encontra na base de todo conhecimento considerado superior, por se tratar de uma noção polissêmica, requer novos olhares que possam distinguir quando o termo estiver relacionado aos elementos das ciências (as disciplinas científicas) e quando denota um sentido didático (disciplinas escolares).

Avançando essa questão, Valente (2015a) problematizou a noção de elementar distinguindo-a da ideia de rudimento.

A ideia de rudimento é algo um tanto difícil de caracterizar, mesmo que procuremos fazer isso por intermédio de um contraponto com a de elemento. De imediato, poder-se-ia dizer que diferentemente de elemento, o rudimento não constitui gérmen de um saber. Sua ligação parece muito mais estar ligada à depuração de temas dos saberes que mais intimamente poderão contribuir para o entendimento e soluções das questões práticas que se apresentam na vida cotidiana. Assim, rudimento articula-se muito mais a finalidades práticas que se esperam de um ensino, e muito menos a uma propedêutica, um encadeamento que seguiria até os saberes avançados(VALENTE, 2015a, p. 196). 
O autor encontra essa distinção em livros didáticos de Aritmética, comparando métodos utilizados por Souza Lobo e Antônio Trajano na organização e estrutura didática dos conteúdos. Destaca que o método intuitivo, vaga que predominou no ensino primário desde o final do século XIX vai sendo incorporado desde os elementos.

Seguindo essa linha de raciocínio, considerando o método como indicador da matriz teórica fundamentada na organização e proposição dos saberes a ensinar, se tem que no Paraná, em 1903, o Regimento Interno das Escolas Públicas do Paraná ao propor uma lista de autores de livros a serem adotados nas escolas, em relação à Aritmética recomendava o nome de Antônio Trajano, autor de vários livros de Aritmética, dentre eles: Aritmética Progressiva, Aritmética Elementar e Aritmética Primária, assim como Primeira Arithmética para meninos, de José Theodoro de Souza Lobo ( PARANÁ, 1903, p. 102).

No Relatório apresentado em 1906 por Bento José Lamenha Lins, ao Presidente do Estado do Paraná Sr. Dr. Vicente Machado da Silva Lima, encontram-se registros de um Inspetor de Ensino tecendo elogios à Aritmética Elementar de Trajano (p. 15), que já havia sido recomendada no Regimento Interno das Escolas Públicas do Paraná, de 1903. No entanto, após uma década, o Conselho Superior de Ensino formado por professores do Gymnásio e Escola Normal determinou que os livros de Trajano fossem substituídos pelos livros Primeira e Segunda Arithmética para meninos, de Souza Lobo.

O uso da Arithmética Elementar de autoria de Antônio Trajano também é mencionado na revista A Escola n. 22, em 1906 (PINTO, 2015). Outro vestígio do uso dessa obra de Trajano é localizado por Claras (2016) na página 49, do Relatório de 1907, da Diretoria da Instrução Pública do Estado do Paraná. A obra de Trajano circulou por longo tempo nas escolas brasileiras, como é possível constatar pelo número de suas edições que em 1927 já alcançara a 59ª edição.

O grande diferencial em reação à obra de Souza Lobo parece ter sido o uso do método analítico que utilizava para organizar e apresentar os conteúdos que eram expostos de forma simples e clara, graduando 
as dificuldades, ilustrados com figuras, contendo exercícios instrutivos e práticos que apresentavam elementos da economia doméstica, da história. O ensino intuitivo, em voga na época, e foi bem destacado nos livros de Trajano possibilitando que os alunos caminhassem do fácil ao difícil.

Entretanto, segundo Valente (2015), o método intuitivo era utilizado por Trajano na introdução das operações e no prosseguimento do ensino o autor retomava o modo tradicional de organização dos conteúdos, de forma lógica, cuja racionalidade não está vinculada ao cotidiano do aluno que aprende. $\mathrm{Na}$ constatação do autor, os saberes elementares matemáticos conservam, pelo menos nos livros analisados, um hibridismo metódico, ou seja, como no caso de Trajano, na análise da totalidade da obra os processos intuitivo-analíticos estão presentes apenas na introdução de temas novos, prosseguindo como fez Souza Lobo com uma ordenação lógica caracterizada como rudimentos.

Observando os diferentes modos adotados pelos autores dos livros didáticos em voga, para ordenar os conteúdos, tudo indica haver uma ruptura entre educação e instrução. Como assinalou Valente (2015), “A primeira considerada herdeira do intelectualismo conteúdista, a segunda, imersa em valores morais e própria para a construção de uma nova sociedade" (p. 199). Tais deslocamentos de método poderiam justificar a substituição no Paraná da obra de Trajano pela de Souza Lobo e a forma hibrida assumida posteriormente por Trajano em sua Arithmética Progressiva.

\section{Considerações finais}

A formação de Mirandolina parece ser uma evidência do pensamento pedagógico centrado nas necessidades anti-intelectualistas, atividades de realização prática voltada para uma vida completa, como bem sinalizou Bulle (apud Valente, 2015, p. 24).

As artes do Desenho, Trabalhos Manuais, Aritmética e Linguagem estão lá no baú de utensílios para o mundo moderno: do esboço do artesão à trama do tecelão, da arte de fazer contas do mercador 
à habilidade de quem sabe ler e escrever, essa base que deu significado à escola elementar constitui-se em vista as finalidades do ensino chamado de elementar.

Se a Mirandolina retornasse em pleno século XXI iria sentir-se estranha por faltar-lhe outro saber para além do ler, escrever e contar, precisaria saber codificar o novo elementar da atual era tecnológica que vivemos.

Nesse sentido, as matrizes teóricas analisadas oferecem indícios sobre finalidades da escola primária em tempos próximos e distantes, quando se trata de buscar novas compreensões do que se ensinava na escola primária do Brasil em tempos de grupos escolares, trazendo evidências das finalidades dessa escola de uma cultura voltada para a vida prática e de outra voltada para a formação geral do cidadão.

Se o avanço desses estudos têm trazido melhores entendimentos das filiações dos saberes elementares matemáticos e sua autenticidade histórica, trouxe também novas questões referentes, principalmente, à forte relação mantida pelos saberes elementares matemáticos com matrizes teóricas impregnadas na cultura profissional dos formadores: na escola primária a ação docente da normalista, guardiã de saberes polivalentes, interdisciplinares, um saber mais prático do que teórico configurado para uma escola terminal; na escola secundária, um saber mais específico de domínio do especialista, um conhecimento mais teórico que prático voltado para um ensino propedêutico.

Em síntese, o estudo procurou discutir matrizes teóricas dos saberes elementares matemáticos, cuja tradição mais forte revelada pelos livros didáticos, em tempos de primeira república, se apresentou mais próxima à corrente filosófica do que a pedagógica, analisadas neste estudo.

Nesse sentido, o estudo traz novas inquietações acerca da complexidade dos saberes elementares matemáticos, abrindo caminho para novas investigações sobrea apropriação da base pedagógica, em tempos nos quais o método era o que impulsionava a escola elementar a superar a velha tradição do ler escrever e contar da escola das primeiras letras. 


\section{Referências}

CHARTIER, R. Inscrever \& Apagar. São Paulo: Editora Unesp, 2007.

CHERVEL, A. História das disciplinas escolares: Reflexões sobre um campo de pesquisa. Teoria \& Educação, Porto Alegre, v. 2, p. 177 - 229, 1990.

CLARAS, A. F. A que servia a Aritmética no ensino primário do Paraná em tempos de Primeira República? 2016. Tese (Doutorado em Educação) - Pontifícia Universidade Católica do Paraná, Curitiba, 2016.

HÉBRARD, J. A escolarização dos saberes elementares na época moderna. Teoria \& Educação. Porto Alegre, n. 2, p. 65 - 110, 1990.

JULIA, D.A cultura escolar como objeto histórico. Revista Brasileira de História da Educação. Campinas: SBHE, n. 1, jan./jul. 2001.

LOUGHLIN, L.N.C. La Educación en Locke. Buenos Aires: Editorial Huemul S.A., 1967.

OLIVEIRA, M. A. Pestalozzi, o método intuitivo e os saberes elementares aritméticos. Método - Cadernos de Trabalho, São Paulo: Editora Livraria da Física, 2015, v. 4.

PARANÁ. Decreto n. 263, de 22 de outubro de 1903. Regimento Interno das Escolas Públicas. Typografia da Penitenciária Geral do Estado: Leis, Decretos e Regulamentos do Estado do Paraná, Curitiba, 1903.

PARANÁ. Relatório Apresentado ao Presidente do Estado do Paraná pelo Bacharel Bento José Lamenha Lins. Curitiba: Tip. Da Penitenciária Geral do Estado, 1906.

PESTALOZZI, J. H. Le Chantdu Cygnesuivi de Mês Destinées. Boufry-Neuchâtel: Édition de La Baconniére, 1947.

PESTALOZZI, J. H. Ecritssurla Méthode. v. 5. Lausanne: LEP Loisirs et Pédagogie, 2013. PINTO, N. B. Aritmética Prática na Revista "A Escola". In: Anais do..., Curitiba, 2015. p. 330-338. 
SOUZA, R. F. Alicerces da pátria: História da escola primária no Estado de São Paulo, 1890-1976. Campinas: Mercado das Letras, 2009.

SOUZA LOBO, J. T. Primeira Arithmética para Meninos. 20. ed. Porto Alegre: Edição da Livraria Globo - Barcellos, Bertaso \& Cia, 1914.

TRAJANO, A. Arithmética Elementar Ilustrada: ensino teórico e prático. 93. ed. Rio de Janeiro: Livraria Francisco Alves, 1924.

TROUVÉ, A. La Notion de Savoir Élémentaire à L'école. Paris: L'Harmattan, 2008.

TROUVÉ, A. Penser L'Élementaire. La fin du savoir élémentaire à l'école? Paris: L'Harmattan, 2010.

VALDEMARIN, V. T. Estudando as Lições de Coisas. Campinas: Autores Associados, 2004.

VALENTE, W. R. Elementar - Cadernos de Trabalho. v. 1. Editora Livraria da Física. São Paulo, 2015a.

VALENTE, W. R. Como Ensinar Matemática no Curso Primário? Uma questão de conteúdos e métodos, 1890-1930. UFMS: Perspectivas da Educação Matemática. v. 8, n. $17,2015 b$.

Recebido: 09/07/2016

Received: 07/09/2016

Aprovado: 15/08/2016

Approved: 15/08/2016 
